\title{
Reinhart Koselleck: histórias no plural ${ }^{*}$
}

\author{
Reinhart Koselleck: Histories in Plural
}

NIKLAS, Olsen. History in the Plural: an Introduction to the Work of Reinhart Koselleck. New York: Berghahn Books, 2012. 346 p.

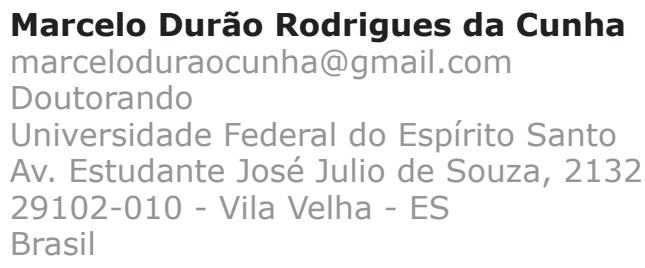

Palavras-chave

Historiografia alemã; História dos conceitos; Reinhart Koselleck.

Keywords

German historiography; History of concepts; Reinhart Koselleck.

294

Recebido em: 1/4/2014

Aprovado em: 8/5/2014

* Pesquisa financiada pela Fundação de Amparo à Pesquisa do Espírito Santo - Fapes. 
Parece estranho que tenha demorado tanto tempo para que o público anglófilo dispusesse de um trabalho introdutório acerca da vida e forma de pensar do clássico historiador alemão Reinhart Koselleck (1923-2006). Ciente da difícil tarefa em tela, o historiador dinamarquês Niklas Olsen justifica na introdução de seu livro que tal atraso talvez se deva à relativa posição de outsider de Koselleck vis-à-vis a profissão histórica. Seu projeto mais conhecido, os sete volumes do Geschichtliche Grundbegriffe, ainda não possui tradução para o inglês, apesar de vários de seus livros, ensaios e artigos já terem sido traduzidos para esse idioma. No Brasil, onde a recepção do intelectual alemão ocorreu de forma um tanto tardia, além de já dispormos da edição de algumas de suas mais importantes obras - como Crítica e crise (1999) e Futuro passado (2006) -, tivemos no ano passado o privilégio de contar com a tradução do verbete "História", retirado do segundo volume do léxico editado por Koselleck. Nestes termos, o conceito koselleckiano de "História" - de cuja versão em português agora dispomos graças à ótima iniciativa de René Gertz - certamente poderá ser melhor compreendido a partir da leitura do profícuo livro de Olsen. Seu título, History in the Plural, alude à ambição de Koselleck de desconstruir aquelas noções utópicas e relativistas de história "no singular", com o objetivo de defender uma concepção "plural" do conceito de história.

O livro - que se trata da tese de doutoramento de Olsen pelo Instituto Europeu de Florença - traz à tona importantes elementos acerca da biografia do historiador saxão, como alguns detalhes referentes à sua participação como soldado na Segunda Guerra Mundial a partir de 1941, sua passagem por Auschwitz após a captura russa em 1945, além dos posteriores quinze meses como prisioneiro de guerra em território soviético. Koselleck, segundo Olsen, faria parte de uma geração de acadêmicos alemães do pós-guerra que de várias formas definiam suas identidades, interesses e crenças a partir de suas experiências com o nacional-socialismo, a guerra e o cativeiro. Koselleck entrou na cena acadêmica nos anos 1950 com a dissertação Crítica e crise, na qual traçava o nascimento do moderno pensamento político desde o Iluminismo. Ele recebeu sua Habilitation em 1965 com o trabalho histórico-social Preussen zwischen Reform und Revolution. Três anos mais tarde se tornou professor em Heidelberg, onde, no assim chamado Arbeitskreis für moderne Sozialgeschichte, teve um papel central no desenvolvimento da moderna história conceitual alemã.

No início dos anos 1970, ao assumir a cátedra de Teoria da História na Universidade de Bielefeld, o historiador também escreveu um amplo número de ensaios a respeito de diferentes temas - a relação entre língua e história social, a ascensão do mundo moderno, questões relacionadas ao tempo histórico, à consciência histórica humana, enunciados teórico-metodológicos e questões filosóficas fundamentais sobre o significado da história e as maneiras pelas quais ela pode ser estudada. Olsen destaca a partir de tal retrospecto que o intelectual continuamente refletia sobre o papel da história na sociedade moderna, diagnosticando as condições políticas de seu tempo, sem se deixar influenciar por um tipo fixo de escrita da história ou por um tipo específico de campo ideológico. É nesses termos que o pesquisador da Universidade de Copenhague visa, nos sete 
capítulos que compõem o seu trabalho, a compreender quais seriam os temas amplos, argumentos e elementos analíticos que estabeleceriam um elo no variado corpo de publicações de Koselleck, como e em quais contextos ele desenvolveu sua obra e o que, mais especificamente, teria sido inovador em seu trabalho.

Buscando tais questões, o livro de Olsen apresenta uma biografia de Koselleck que se propõe ao mesmo tempo a examinar o seu trabalho e os contextos intelectuais e sociais nos quais ele surgiu. Para tal, o historiador parte do pressuposto de que a produção acadêmica de Koselleck não pode ser compreendida a partir de uma única perspectiva. Ao invés de apresentar o método, a teoria, a política, experiências pessoais, fatores institucionais, questões de identidade ou formas narrativas como centro epistemológico de sua produção de escrita histórica, sua investigação enfoca todas essas perspectivas e sua mútua relação.

Em tal sentido Olsen parte em princípio da caracterização de Koselleck como um "partidário" de "histórias no plural", contrário à história no singular, como comentado pelo filósofo Jacob Taubes (1923-1987) no início dos anos 1970. Em oposição a ideias histórico-filosóficas da história que a apresentavam como um projeto unificado e progressivo no qual os seres humanos se programam e se direcionam para um objetivo final, Koselleck almejava tematizar um modo de escrita que visse a história como composta por uma pluralidade de histórias não convergentes que jamais poderiam ser arquitetadas de acordo com o desejo humano.

296 o livro também descortina um argumento mais específico acerca do trabalho de Koselleck. Olsen mostra que as críticas do autor às filosofias históricas também continham uma crítica a certo tipo de relativismo como uma noção baseada no mesmo pressuposto conceitual: a história no singular. Assim como a concepção de história utópica, teleológica que ele identificava como característica de boa parte dos escritos históricos desde o século XVIII, esse tipo de relativismo pressupunha a ideia de que seria possível formular uma posição teórica coerente sobre a história como uma totalidade. Segundo Olsen, o historiador alemão acreditava que a utopia e o relativismo se baseavam em pressupostos teórico-metodológicos ingênuos e politicamente perigosos que ignoravam ou não compreendiam as condições básicas das possibilidades humanas.

E isso nos leva ao argumento central da obra em questão: os escritos de Koselleck estariam sempre relacionados à ambição de estabelecer compreensões e visões de ciência e da política que iriam além da utopia e do relativismo. 0 ponto crucial seria o de que Koselleck insistiria em que a história deve ser plural, devendo ser escrita a partir de pontos de vista que também fossem plurais. Dessa perspectiva pluralista e em contraste com o relativismo, ele ambicionava estabelecer um ponto de vista estável, comum e não relativista a partir do qual a mudança histórica pudesse ser descrita em um parâmetro de julgamento em cuja base passado e presente pudessem ser discutidos sem cair nas armadilhas da utopia. Essa ambição e os elementos discursivos a ela relacionados revelariam, para Olsen, um padrão e um objetivo comuns em seu amplo corpo de trabalho. 
É em tais termos que o autor busca descrever a formação intelectual de Koselleck no amplo sentido de um processo de formação de um indivíduo acadêmico, definido em parte pelo habitus e em parte por um específico aparato de objetivos intelectuais. Olsen argumenta que cinco pensadores tiveram influência central no desenvolvimento intelectual de Koselleck. Seu orientador de doutorado foi Johannes Kuhn, e com ele o jovem acadêmico aprendeu o ofício de historiador, bem como a compreender a temática histórica da tolerância tal qual perscrutada por seu mestre. Do livro Meaning in History - que Koselleck ajudou a traduzir -, de Karl Löwith, o estudante de Heidelberg absorveu a ideia de escatologia secularizada, além do ceticismo quanto à noção de história como um projeto progressivo singular. Carl Schmitt se tornou um mentor informal de Koselleck enquanto ele trabalhava em sua dissertação, e, assim, o autor de Crítica e crise incorporou das reflexões de Schmitt em torno da derrota alemã a teoria de sobre como os "derrotados" na história são aqueles que desenvolvem novas ferramentas metodológicas e insights na tentativa de compreender sua experiência negativa. ${ }^{1}$ Hans Georg-Gadamer foi convidado para Heidelberg em 1949, e sua abordagem hermenêutica da história influenciou a visão de Koselleck sobre como os humanos agem e compreendem o mundo. Finalmente, o trabalho de Martin Heidegger inspirou dois dos mais importantes projetos intelectuais de Koselleck: uma percepção antropologicamente embasada sobre como a história é criada/compreendida e uma teoria do tempo histórico entendida a partir da compreensão da concepção de tempo dos atores históricos.

É sob tal prisma que Olsen analisa a dissertação Crítica e crise, considerando as influências intelectuais do autor e situando sua obra no contexto dos debates acadêmicos do período pós-guerra, levando em consideração a relação entre os extremos eventos políticos do século XX e o pensamento iluminista. Mais concretamente, Olsen expõe como em tal trabalho Koselleck descrevia o moderno pensamento político como tendo surgido em torno da Revolução Francesa, caracterizado por elementos perigosos, irresponsáveis e utópicos que teriam gerado um mundo moderno dominado por permanente crise, revolução e guerra civil. Isso é seguido por uma discussão sobre a agenda normativa da interpretação de Koselleck e sobre a extensão em que sua concepção do processo de secularização e das relações entre moral e política no estudo coincidiu com o trabalho de seus professores e divergiu dele.

Olsen também demonstra como, nos anos entre sua dissertação e sua Habilitation, Koselleck remoldou seu pensamento e se reposicionou como um acadêmico mais convencional e amplamente respeitado em seu meio. Tendo como foco o processo de recepção, o livro de Olsen nos mostra como o intelectual desenvolveu uma teoria da dinâmica histórica da geografia política com a qual ele substanciou seus argumentos concernentes à necessidade de respeitar a condição antropológica dos seres humanos, colocando em prática, além disso, uma perspectiva analítica que se tornou uma parte integral de seu pensamento histórico em termos mais gerais. 
Nesse período de trabalho em Heidelberg, sob a supervisão de Werner Conze (1910-1986), Koselleck se aproximaria de um tipo mais tradicional de história social e estrutural. A intervenção de Conze durante a escrita de Preussen zwischen Reform und Revolution evidenciava, segundo Olsen, a continuidade de normas culturais de longo termo e de estruturas sociais na academia alemã que conformavam um sistema no qual estudantes mais jovens eram amplamente dependentes da boa vontade e das decisões de seus professores. Em que pese a influência de tais normas e formalismos acadêmicos mais tradicionais, Koselleck não deixaria de usufruir do campo da história social na descoberta de um grande número de elementos discursivos com os quais ele encontrou novas formas de desconstruir a história no singular e escrever a história no plural.

Tal lógica seria evidenciada na aproximação, ainda nos anos em Heidelberg, entre o jovem historiador alemão e as ideias do medievalista Otto Brunner (1898-1982). Ao enfatizar a relação entre conceitos sociopolíticos, a contestação político-social e a mudança, Koselleck se referia a uma abordagem conceitual conectada ao nascimento da moderna história conceitual alemã, como articulado nos estudos socioconstitucionais de Brunner nos anos de 1930 e 1940. Num plano geral, ele encontrou na abordagem de Brunner - que posteriormente ele denominaria "historicismo consequente" - um mecanismo analítico para conter o que ele via como as dimensões a-históricas da antiga tradição historicista alemã.

Indo além, Olsen defende que o que Koselleck queria com sua análise conceitual era criticar os componentes linguísticos das modernas ideias utópico298 -filosóficas da história a partir da demonstração da natureza plural, diversa e contestada da linguagem e da política. Nesse sentido, ele ambicionaria inscrever uma perspectiva sobre contextos sociais mais concretos e contestações naquele quadro. Para a sua proposta, ele teria continuado seu diálogo e sua demarcação a partir da tradição da história conceitual como praticada por Carl Schmitt.

A tentativa de Koselleck de trazer os aspectos da realidade social, da luta e das mudanças não era ambicionada apenas em relação ao essencialismo da abordagem conceitual de Schmitt. Ela também estava indiretamente voltada contra as visões essencialistas de Heidegger sobre a língua como o sistema de toda a existência humana e contra as noções de linguagem em Gadamer relacionadas como a chave para toda realidade humana. No fim, essa era uma dimensão crucial no esquema conceitual da abordagem histórica pragmática da linguagem em Koselleck, divergindo daquela de suas fontes de inspiração num plano bastante básico.

Um dos objetivos de Olsen também é iluminar como Koselleck, como historiador e professor universitário, reagiu às várias mudanças e desafios relacionados à profissão histórica no fim dos anos 1960 e início dos 1970, apontando a maneira pela qual os Geschichtliche Grundbegriffe contribuíram - também politicamente - para a estabilização de sua imagem como um importante porta-voz da ciência histórica alemã naquele período. O autor escandinavo esclarece que o escopo desse trabalho - que talvez tenha sido o mais ambicioso projeto de Koselleck - seria o de iluminar a transição para o mundo moderno a partir da análise de mudanças em conceitos sociais e 
políticos ocorridas, sobretudo, nos estados alemães ao longo do período entre 1750 e 1850, referenciado pelo autor a partir da ideia de Sattelzeit. A noção remontava a como, nesse período, amplas mudanças político-sociais teriam ocorrido simultaneamente a transformações fundamentais na topografia conceitual, de modo que conceitos políticos e sociais básicos teriam adquirido significados que não mais precisavam ser traduzidos para serem compreendidos na contemporaneidade.

Um último esforço é feito por Olsen em sua tentativa de explorar os debates de Koselleck no que diz respeito à experiência de guerra, da violência e do terror e de posicionar esses escritos no interior de uma gama mais ampla da produção acadêmica do historiador alemão. Sua perspectiva se baseava em uma tentativa de descrever as formas pelas quais os limites da condição humana foram experimentados pelas vítimas da Segunda Guerra Mundial e do nacional-socialismo e em uma interpretação do Holocausto como uma ruptura radical na história, que, de acordo com Koselleck, com sua extrema violência e sofrimento, questionara qualquer noção de significado na história, tendo trazido novos desafios a respeito de como a realidade experimentada pode ser exposta, comunicada e compreendida. Assim, Olsen aponta que o objetivo de Koselleck era o de demonstrar que os seres humanos interpretam e dão sentido a suas experiências mais extremas de formas diferentes ou plurais que não podem ser completamente entendidas ou compartilhadas por outros. Olsen também mostra que a nova perspectiva de Koselleck sobre a história no plural, adotada no fim de sua carreira, também passou a envolver uma mudança analítica de foco das coletividades para o indivíduo que ocorreu lado a lado com uma defesa da experiência individual contra as amplas noções da memória coletiva.

A relevância e o legado do intelectual alemão são enaltecidos por Olsen na última parte de seu trabalho, quando afirma que, enquanto o habitus do programa e da carreira de Koselleck como acadêmico teria sido único em muitos aspectos, o objetivo principal do seu programa evidentemente transcenderia sua vida e obra. Explicar (historicamente) e conter (politicamente) os latentes prospectos do conflito violento nas sociedades humanas é um desafio que continua a ocupar os seres humanos. Olsen acrescenta que, desde que Koselleck passou a enfatizar o pluralismo, a maioria dos historiadores se moveu, concomitantemente, para além da utopia e do relativismo. Contudo, seu trabalho se afastaria do mainstream da pesquisa histórica em função de sua tentativa específica de prover sentido teórico à pluralidade da história humana e de explorar essa amplitude a partir da pesquisa empírica. Assim, concordando com o autor dinamarquês, não restam dúvidas de que Koselleck nos ofereceu um extraordinariamente compreensível e aplicável leque de ferramentas para colocar em prática o desafio da pluralidade histórica no sentido de analisar de onde nós viemos, qual é a nossa situação atual e qual futuro pode nos aguardar.

As dimensões temporais, espaciais e linguísticas da avassaladora crise de consciência em torno da economia global, as profundas constelações da relação "amigo/inimigo" no Oriente Médio e o crescente antagonismo do fenômeno da não simultaneidade (ungleichzeitige) entre globalização e nacionalismo são 
apenas três dos muitos exemplos de questões contemporâneas que teorias e métodos da vasta obra de Koselleck poderiam ajudar-nos a compreender. Assim, já tarda a ocasião para uma ampla e mais compreensiva recepção de seu trabalho e para o correlativo debate, algo que certamente pode ser esperado em um futuro próximo na historiografia brasileira e estrangeira, como já é possível perceber na introdução proposta por Olsen.

\section{Referências bibliográficas}

KOSELLECK, Reinhart. Preußenzwischen Reform und Revolution: Allgemeines Landrecht, Verwaltung und soziale Bewegung von 1791 bis 1848. Stuttgart: Klett-Cotta, 1967.

Crítica e crise: uma contribuição à patogênese do mundo burguês. Rio de Janeiro: EdUERJ; Contraponto, 1999.

. Los estratos del tiempo: estudios sobre la historia. Barcelona: Paidós, 2001.

. The Practice of Conceptual History: Timing History, Spacing Concepts. Stanford: Stanford University Press, 2002.

. Historia/historia. Madrid: Trotta, 2004.

Futuro passado: contribuição à semântica dos tempos históricos. Rio de Janeiro: Contraponto; Ed. PUC-Rio, 2006. 